\title{
Hipotireoidismo na espécie canina: avaliação da ultra-sonografia cervical como metodologia diagnóstica
}

Viviani De MARCO ${ }^{1}$

Carlos Eduardo LARSSON ${ }^{2}$

\section{Correspondência para:}

VIVIANI DE MARCO

Clínica Médica de Pequenos Animais

Faculdade de Medicina Veterinária

Universidade Guarulhos

R. Anton Philips, portão 3 - Hospital

Veterinário

07030-010-Guarulhos-SP

vivianidemarco@terra.com.br

Recebido para publicação: 17/08/2004 Aprovado para publicação: 01/06/2005

\author{
1 - Clínica Médica de Pequenos Animais da Faculdade de Medicina \\ Veterinária da Universidade Guarulhos, Guarulhos - SP \\ 2 - Departamento de Clínica Médica da Faculdade de Medicina Veterinária e \\ Zootecnia da Universidade de São Paulo, São Paulo - SP
}

\section{Resumo}

O objetivo do presente estudo foi avaliar a ultra-sonografia das glândulas tireóides em animais com hipotireoidismo primário. Foram utilizados dez cães hipotireoideos, diagnosticados, através de anamnese, exame físico e exames laboratoriais, tais como dosagens séricas de T4 total, T4 livre, TSH, colesterol e triglicérides; e 10 cães eutireoideos A ultra-sonografia cervical revelou nítida redução do volume total da glândula tireóide em todos os animais hipotireoideos, estatisticamente significante $(p<0,05)$, em comparação aos animais considerados eutireoideos, denotando, assim, a existência de atrofia glandular, secundária ao hipotireoidismo.

\section{Introdução}

O hipotireoidismo primário, uma das endocrinopatias mais comuns da espécie canina ${ }^{1}$, resulta, em mais de $95 \%$ dos casos, da perda progressiva de tecido tireoidiano funcional, devido à disfunção primária da glândula com consequente redução dos níveis séricos do hormônio circulante ${ }^{2}$. Tal destruição do parênquima parece advir de dois mecanismos etiopatogênicos distintos, quais sejam, a tireoidite linfocítica ou a atrofia idiopática ${ }^{3}$.

Essa disfunção hormonal acomete, principalmente, cães de médio ou grande porte, entre 4 e 8 anos de idade ${ }^{4}$. As raças mais predispostas são: Golden Retriever, Labrador, Dobberman, Cocker Spaniel, Poodle, Beagle, Chow chow $^{5}$, Dachshund e Airedale. Fêmeas castradas apresentam maior risco de acometimento. Dentre os sintomas clínicos manifestados, destacam-se: termofilia, intolerância a exercícios, ganho de peso $^{7}$, letargia, depressão, alterações tegumentares ${ }^{9,10}$, reprodutivas, cardiovasculares, neurológicas e musculares ${ }^{11}$, além do mixedema facial, caracterizado pela "facies tragica"
Para a consecução do correto diagnóstico do hipotireoidismo, é necessário que se alie os dados anamnésticos, aos achados dos exames físicos e laboratoriais. Dentre estes últimos, incluem-se: as dosagens séricas de colesterol e de triglicérides e, principalmente, as mensurações dos hormônios tireoidianos. A determinação da relação recíproca das concentrações baixas de T4 total, T4 livre e altos níveis séricos de TSH aumenta significantemente a acurácia do diagnóstico ${ }^{11,13,14}$.

Com relação às modalidades de diagnóstico por imagem que podem ser utilizadas para acessar a glândula tireóide, no que diz respeito ao tamanho, à forma, à presença de lesões císticas, sólidas e calcificações, o exame ultra-sonográfico é um meio diagnóstico bastante explorado, porém, apenas, em medicina humana. Em medicina veterinária, seu uso restringe-se à pesquisa de eventuais presenças de formações neoplásicas tireoidianas, porém pode também propiciar importantes elementos anátomo-topográficos, empregados para a elucidação diagnóstica do hipotireoidismo, bem como auxiliar no diagnóstico diferencial da "síndrome do 
eutireoideo doente" (condição esta caracterizada por níveis baixos de T4 total, secundariamente a doenças crônicas não tireoidianas) $^{15}$. A glândula tireóide, num plano longitudinal, apresenta-se como estrutura fusiforme homogênea, e como estrutura triangular, num plano transversal, medialmente à artéria carótida comum e caudal à laringe na região cervical cranial. Sua ecogenicidade é inferior à adventícia que a circunda, mas superior à musculatura cervical. ${ }^{16,17}$ Nos quadros de hipotireoidismo primário, o ultra-som poderá revelar redução do tamanho dos lobos tireoideanos e, ainda, alterações de ecogenicidade ou de forma, quando comparados a um lobo tireoideano normal ${ }^{15}$.

Apesar das preciosas informações que a ultra-sonografia cervical pode nos oferecer, o aspecto ultra-sonográfico das glândulas tireóides de cães hipotireoideos não está ainda bem estabelecido

\section{Objetivos}

Os objetivos do presente trabalho foram: descrever as características ultrasonográficas das glândulas tireóides, no que diz respeito ao tamanho glandular, em cães hígidos e naqueles portadores de hipotireoidismo; e avaliar a exequibilidade do exame ultra-sonográfico em cães tireopatas.

\section{Material e Métodos}

A amostragem foi composta por vinte animais, da espécie canina, atendidos no Serviço de Dermatologia do Departamento de Clínica Médica (VCM) e do Hospital Veterinário (HOVET) da Faculdade de Medicina Veterinária e Zootecnia da Universidade de São Paulo (FMVZ-USP), e reunida em dois grupos, a saber: Grupo 1, composto por dez animais hipotireoideos e Grupo 2, composto por dez animais hígidos.

Não houve restrições raciais ou sexuais para a constituição dos dois grupos. Porém, quando da seleção dos animais que compuseram o Grupo 2, escolheram-se aqueles com peso semelhante ao dos animais do grupo 1, a fim de se obter populações homogêneas, e com idade entre oito e doze meses, sendo improvável o desenvolvimento do hipotireoidismo primário com atrofia da glândula tireóide, em animais dessa faixa etária. Os animais do Grupo 2 não apresentavam qualquer sintomatologia clínica sistêmica condizente com hipotireoidismo ou mesmo alterações tegumentares.

O diagnóstico da enfermidade dos animais endocrinopatas foi baseado em judiciosa anamnese, em minucioso exame físico, na avaliação de exames laboratoriais como dosagens séricas de colesterol (CHOD-PAP Enzi-color-Cód.1148300001 Merk. Cód. Bayer: 25389900) e triglicérides (Método enzimático Sera-Pak (Bayer Corporation cód. 6687), exame ultrasonográfico da glândula tireóide e, principalmente, das determinações hormonais basais, por ensaio radioimunométrico, de tiroxina sérica total (T4) e TSH canino, e da fração livre e biologicamente ativa da tiroxina (T4 L), através de diálise de equilíbrio.

Utilizou-se de aparelho Analizer RA-100 (Technicon Bayer) para a execução dos exames bioquímicos séricos (triglicérides e colesterol). A colheita de sangue se processou por venipunção das veias radial, safena e/ou jugular. Com exceção das determinações hormonais, encaminhadas a laboratório particular especializado (Labvet - São Paulo), os demais exames foram realizados no Serviço de Laboratório Clínico do Departamento de Clínica Médica da FMVZ-USP. Todas as determinações laboratoriais foram efetuadas, visando a consecução do diagnóstico etiológico, ou seja, previamente ao início do tratamento.

O exame ultra-sonográfico cervical, para avaliação das glândulas tireóides, foi executado com o aparelho ultra-sonográfico EUB 405 HITACHI com transdutores de 7,5 e 10 MHZ. Para uma melhor avaliação glândular, utilizou-se o cálculo do volume 
da glândula, estimado pela equação $0^{18,19}$ :

Volume total glandular $\left(\mathrm{cm}^{3}\right)=$ VTD + VTE, onde:

Volume tireóide direita $\left(\mathrm{VTD}^{3} \mathrm{~cm}^{3}\right)=$ comprimento $(\mathrm{cm})$ x largura $(\mathrm{cm}) \mathrm{x}$ espessura $(\mathrm{cm}) \times \mathrm{p} / 6$

Volume tireóide esquerda $\left(\mathrm{VTEcm}^{3}\right)$ $=$ comprimento $(\mathrm{cm}) \times$ largura $(\mathrm{cm}) \times$ espessura $(\mathrm{cm}) \times \mathrm{p} / 6$

Tal fórmula, destinada à determinação de volumes de formas elípticas, têm sido, amplamente, empregada em medicina humana para cálculo do volume tireoidiano ${ }^{18,19}$. Os valores obtidos foram confrontados com aqueles achados nos animais-controle Grupo 2, que apresentavam peso semelhante aos cães do Grupo 1, uma vez que existe uma correlação positiva entre o peso do animal e o volume da glândula tireóide.

\section{Análise estatística}

Os resultados obtidos com a avaliação das glândulas tireóides dos animais hipotireoideos e dos animais hígidos, no que diz respeito ao tamanho glandular, foram analisados através do teste paramétrico $t$ student para medidas independentes com nível de significância de 5\% ( $\mathrm{p}<0.05)$, uma vez que a população estudada apresentouse com distribuição normal, evidenciada pelo teste Kolmogorov-Smirnov.

\section{Resultados}

\section{Grupo 1 - Animais com hipotireoidismo}

Dos dez animais hipotireoideos estudados, oito $(80 \%)$ eram fêmeas e sete (70\%) apresentavam definição racial, a saber: Poodle (2), Pit Bull (1), Chow chow (1), Dacshund (1), Dobberman (1) e Terrier Brasileiro (1). A média e o desvio padrão obtidos a partir da idade e do peso corpóreo desses animais foram, respectivamente: 5,3 e 0,9 anos e 17,6 e 11,6 quilogramas.

A tabela 1 ilustra os valores médios e respectivos desvios padrões das determinações séricas de colesterol, triglicérides, T4 total, T4 livre e TSH. O quadro 1 revela as mensurações individuais de comprimento, largura e espessura das glândulas tireóides direita e esquerda, bem como o cálculo do volume glandular total nos animais com hipotireoidismo. As Figuras 1 e 2 ilustram imagens ultra-sonográficas da glândula tireóide de um animal com hipotireoidismo no plano transversal e no plano longitudinal, respectivamente.

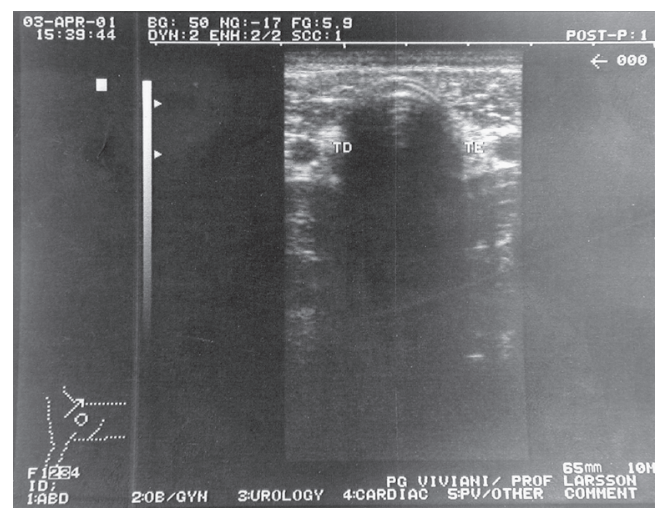

Figura 1 - Imagem ultra-sonográfica de glândula tireóide de animal com hipotireoidismo, no plano transversal

\section{Grupo 2 - Animais hígidos}

Dentre os dez animais que compuseram este Grupo, seis (60\%) eram machos e sete $(70 \%)$ apresentaram definição racial, tais como: Poodle (2), Pit Bull (2), Cocker (1), Schnauzer (1) e Dacshund (1). As médias e os desvios padrões da idade, do peso corpóreo e do volume total da

Tabela 1 - Valores da média e do desvio padrão das determinações séricas de colesterol, triglicérides, T4 total, T4 livre e TSH dos dez animais com hipotireoidismo. FMVZ-USP (2000-2001)

\begin{tabular}{cccccc}
\hline & Colesterol & Triglicérides & T4 total & T4 livre & TSH \\
\hline Média & 384,3 & 265,0 & 5,6 & 1,4 & 38,5 \\
Desvio padrão & 200,5 & 151,7 & 2,9 & 1,4 & 18,1 \\
\hline \multirow{2}{*}{ Valores de referência } & $\begin{array}{c}100-300 \\
(\mathrm{mg} / \mathrm{dl})\end{array}$ & $\begin{array}{c}100-200 \\
(\mathrm{mg} / \mathrm{dl})\end{array}$ & $\begin{array}{c}15-50 \\
(\mathrm{nmol} / \mathrm{L})\end{array}$ & $\begin{array}{c}9-40 \\
(\mathrm{pmol} / \mathrm{L})\end{array}$ & $\begin{array}{c}0-30 \\
(\mathrm{um} / \mathrm{L})\end{array}$ \\
\hline
\end{tabular}




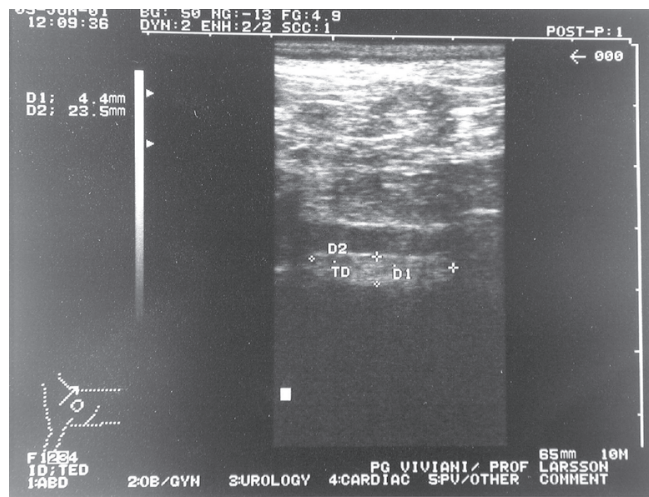

Figura 2-Imagem ultra-sonográfica de glândula tireóide de animal com hipotireoidismo, no plano longitudinal

glândula tireóide foram, respectivamente, de: 0,89 e 0,11 anos, 17,5 e 7,5 quilogramas, 0,54 e $0,18 \mathrm{~cm}^{3}$.

A análise da tabela 2 propicia a comparação dos valores da média, desvio padrão e de "p", calculados a partir das mensurações provenientes da avaliação ultrasonográfica das glândulas tireóides, entre animais doentes e hígidos, ou seja, Grupos 1 e 2 . A figura 3 ilustra, comparativamente,

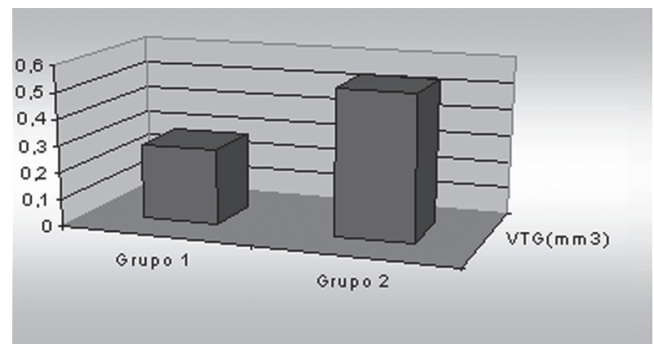

Figura 3 - Comparação entre os valores da média dos volumes totais glandulares da tireóide dos animais do Grupo 1 (hipotireoidismo) edo Grupo 2 (controle). FMVZ-USP (2001)

os valores médios de volume total da glândula tireóide dos animais hipotireoideos (Grupo 1) e dos animais hígidos (Grupo 2).

\section{Discussão}

Avaliação clínico-laboratorial dos animais com hipotireoidismo

A predisposição racial, sexual e etária dos animais hipotireoideos, assim como o cortejo mórbido manifestado por eles, e que, clinicamente, caracterizou-se por: apatia, abulia, letargia, obesidade, termofilia,

Tabela 2 - Comparação entre os valores da média, desvio padrão e " $p$ " dos volumes totais glandulares da tireóidee dos pesos dos animais do Grupo 1 e do Grupo 2. FMVZ-USP (2001)

\begin{tabular}{ccc} 
Grupo & Peso $(\mathrm{kg})$ & Volume total glandular $($ VTG cm \\
\hline $\mathrm{I}$ & $17,59+/-11,88$ & $0,28+/-0,19$ \\
$\mathrm{II}$ & $17,5+/-7,5$ & $0,54+/-0,18$ \\
\hline " $\mathrm{p}$ " (probabilidade) & 0,94 & $0,01^{*}$ \\
\hline
\end{tabular}

\begin{tabular}{|c|c|c|c|c|c|c|c|}
\hline \multirow{2}{*}{$\begin{array}{l}\text { Prontuários* } \\
\text { (números) }\end{array}$} & \multicolumn{3}{|c|}{ Tireóide Direita $\left(\mathrm{cm}^{3}\right)$} & \multicolumn{3}{|c|}{ Tireóide Esquerda $\left(\mathrm{cm}^{3}\right)$} & \multirow{2}{*}{$\frac{\text { VTG }\left(\mathrm{cm}^{3}\right)}{(T D+T E)}$} \\
\hline & $\mathrm{C}(\mathrm{cm})$ & $\mathrm{L}(\mathrm{cm})$ & $\mathrm{E}(\mathrm{cm})$ & $\mathrm{C}(\mathrm{cm})$ & $\mathrm{L}(\mathrm{cm})$ & $\mathrm{E}(\mathrm{cm})$ & \\
\hline 111466 & 2,0 & 0,3 & 0,4 & 2,2 & 0,3 & 0,4 & 0,26 \\
\hline 105510 & 2,0 & 0,3 & 0,3 & 2,0 & 0,25 & 0,25 & 0,16 \\
\hline 114618 & 0,9 & 0,29 & 0,35 & 1,2 & 0,34 & 0,45 & 0,14 \\
\hline 114594 & 1,3 & 0,29 & 0,54 & 1,47 & 0,24 & 0,47 & 0,18 \\
\hline 113512 & 1,27 & 0,32 & 0,42 & 1,74 & 0,29 & 0,38 & 0,18 \\
\hline 114622 & 2,4 & 0,3 & 0,4 & 2,7 & 0,34 & 0,35 & 0,30 \\
\hline 112666 & 1,1 & 0,42 & 0,39 & 1,56 & 0,4 & 0,37 & 0,30 \\
\hline 116549 & 2,8 & 0,52 & 0,6 & 2,3 & 0,5 & 0,61 & 0,80 \\
\hline 70447 & 1,97 & 0,39 & 0,45 & 2,0 & 0,38 & 0,48 & 0,30 \\
\hline 117936 & 2,98 & 0,26 & 0,3 & 1,89 & 0,3 & 0,29 & 0,20 \\
\hline
\end{tabular}

Quadro 1 - Resultados do exame ultra-sonográfico de glândulas tireóides de dez cães com hipotireoidismo. FMVZ-USP (2000-2001)

$\mathrm{VTG}=$ volume total glandular; $\mathrm{TD}=$ tireóide direita; $\mathrm{TE}=$ tireóide esquerda, $\mathrm{C}=$ comprimento; $\mathrm{L}=$ largura; $\mathrm{E}=$ espessura. *Registrados no HOVET-USP 
alterações no sistema músculo-esquelético, reprodutivo e, notadamente, no sistema tegumentar, apresentou plena concordância com os dados dispostos na bibliografia especializada ${ }^{15,20,21}$.No tocante aos resultados dos exames de bioquímica sérica, constatouse evidente hipercolesterolemia e hipertrigliceridemia em, respectivamente, $60 \%$ e $70 \%$ dos animais do Grupo 1. Estes achados superpõem-se àqueles citados por Panciera ${ }^{10}$ e ocorrem em decorrência do menor metabolismo lipídico ocasionado pelo déficit de tiroxina $^{15}$. A avaliação da função tireoideana revelou níveis de T4 total e T4 livre, bastante inferiores (Tabela1) àqueles valores ditos de referência, na totalidade da amostragem (Grupo 1), propiciando elementos para a confirmação da suspeição diagnóstica. Já os níveis séricos de TSH canino mostraram-se elevados em $60 \%$ dos casos, uma vez que, mesmo inexistindo o feedback negativo do T4 e T3 sobre a glândula hipófise, as concentrações séricas de TSH podem estar normais em $38 \%$ dos casos de hipotireoidismo ${ }^{10,22}$.

\section{Avaliação da Ultra-sonografia Cervical}

A ultra-sonografia cervical não é, rotineiramente, executada no Brasil, em cães com suspeita de hipotireoidismo, além do que, as anormalidades ultra-sonográficas da glândula tireóide não têm sido estudadas na sua plenitude ${ }^{15}$. No seu maior eixo (plano longitudinal), cada glândula tireóide foi visualizada como uma estrutura fusiforme, homogênea, bem delimitada, medial à artéria carótida comum, na região cervical ventrocranial. Sua ecogenicidade mostrou-se inferior àquela da musculatura cervical na totalidade dos animais com hipotireoidismo (Grupo 1), porém superior em todos os animais controle (Grupo 2), como é o de se esperar em animais eutireoideos. No plano transversal, a glândula tireóide mostrou-se com formato triangular, situando-se medialmente à artéria carótida comum e lateralmente à traquéia no cão, conforme descrições previamente relatadas ${ }^{17}$.

Não foram evidenciadas lesões, císticas ou sólidas, e tampouco calcificações, em nenhuma das glândulas examinadas, nos vinte animais submetidos à ultra-sonografia cervical. Porém, diferenças significativas puderam ser detectadas quanto ao tamanho da glândula, comparando-se o grupo de animais hipotireoideos (Grupo 1) com aquele dos animais hígidos (Grupo 2). Portanto, todas as glândulas tireóides, examinadas nos vinte animais, apresentaramse homogêneas.

A média do volume total da glândula tireóide (VTG) de animais com hipotireoidismo foi de $0,28 \mathrm{~cm}^{3}$, ou seja, metade do valor da média do VTG dos animais hígidos, qual seja, $0,54 \mathrm{~cm}^{3}$, demonstrando inequivocamente a presença de atrofia glandular (Figura 3). Embora os pesos corpóreos tenham se mostrado bastante variáveis dentre os animais pertencentes aos Grupos 1 e 2, ao se empregar o teste Kolmogorov-Smirnov, verificou-se que ambos os grupos apresentaram distribuição normal. Sendo assim, utilizou-se o teste paramétrico t-student, que permitiu que se constatasse que os volumes glandulares totais do grupo de animais com hipotireoidismo foram significantemente inferiores $(\mathrm{p}=0,01)$ àqueles obtidos no Grupo controle (Quadro 2).

\section{Conclusões}

A ultra-sonografia cervical possibilitou evidenciar a presença de atrofia da glândula tireóide na totalidade dos casos de hipotireoidismo; a ultra-sonografia das glândulas tireóides mostrou-se exequível, provando ser meio semiológico indireto de grande valia no auxílio do diagnóstico de tireoidepatias caninas.

\section{Agradecimentos}

Dra. Márcia M. Jericó; Dra. Gracziela Zeo; Dr. Eduardo Kiyoshi Tomimori; Dra. Rosalinda Yossie Asato de Camargo; FAPESP. 


\title{
Hypothyroidism in dogs: study of cervical ultrasonography as diagnosis methodology
}

\begin{abstract}
The aim of this study is to evaluate cervical ultrasonography as methods for diagnosis of hypothyroidism. Twenty dogs were distributed in 2 groups: 10 dogs with hypothyroidism, and 10 healthy dogs as a control group. All dogs were submitted to ultrasonographic examination in the cervical area. To confirm hypothyroidism diagnosis, total T4, free T4 and TSH hormones samples were obtained and, also, cholestherol and triglycerides. Hypothyroid animals submitted to cervical ultrasonography showed marked reduction in the total volume of the thyroid gland, with statistical significance $(\mathrm{p}<0,05)$, in comparison to normal dogs. This alteration demonstrated the gland atrophy secondary to hypothyroidism.
\end{abstract}

\section{Referências}

1 CHASTAIN, C. B.; GAIJAM, V. K. (Ed.). Clinical endocrinology of companion animals. Philadelphia: Lea \& Febiger, 1986. 568 p.

2 FELDMAN, E. C.; NELSON, R. W. Canine and feline endocrinology and reproduction. Philadelphia: W.B. Saunders, 1996. 785 p.

3 KEMPPAINEN, R. J.; CLARK, T. P. Etiopathogenesis of canine hypothyroidism. Veterinary Clinics of North America. Small Animal Practice, v. 24, n. 3, p. 467476, 1994.

4 SCARLETT, J. M. Epidemiology of thyroid diseases of dogs and cats. Veterinary Clinics of North America. Small Animal Practice. v. 24, n. 3, p. 478, 1994

5 PANCIERA, D. L. Canine hypothyroidism. Part I Clinical findings and control of thyroid hormone secretion and metabolism. The Compendium on Continuing Education for the Practicing Veterinarians, v. 12, n. 5 , p. 689-698, 1990.

6 MILNE, K. L.; HAYES, H. M. Epidemiologic features of canine hypothyroidism. Cornell Veterinary, v. 71, n. 1, p. 3-14, 1981.

7 DIXON, R. M.;REID, S. W. J.; MOONEY, C. T. Epidemiological, clinical, haematologicl and biochemical characteristics of canine hypothyroidism. Veterinary Record, v. 145, n. 17, p. 481, 1999.

8 GRECO, D. S.; ROSYCHUK, R. A. N.; OGILVIE, G. K.; HARPOLD, L. M.; LIEW, C. H Van. The effect of levothyroxine treatment on resting energy expenditure of hypothyroid dogs. Journal of Veterinary Internal Medicine, v. 12, n. 1, p. 7-10, 1998.

9 DIXON, R. M.; GRAHAM, P. A.; MOONEY, C. T. Serum thyrotropin concentrations: a new diagnostic test for canine hypothyroidism. Veterinary Record, $\mathrm{v}$. 138, n. 24, p. 594-595, 1996.
10 PANCIERA, D. L. Is it possible to diagnose canine hypothyroidism? Journal of Small Animal Practice, v. 40, n. 4, p. 152-157, 1999.

11 PANCIERA, D. L. Clinical manifestations of canine hypothyroidism. Symposium on canine hypothiroidism. Veterinary Medicine, v. 92, n. 1, p. 44-57, 1997.

12 SCOTT-MONCRIEFF, J. C.; NELSON, R. W. BRUNER, J. M.; WILLIANS, D. A. Comparison of serum concentrations of thyroid-stimulation hormone in healthy dogs, hypothyroid dogs, and euthyroid dogs with concurrent disease. Journal of the American Veterinary Medical Association, v. 212, n. 3, p. 387391, 1998.

13 KEMPPAINEM, R. J.; BEHREND, E. N. CVT Update: Interpretation of endocrine diagnostic test results for adrenal and thyroid disease. In: BONAGURA, J. D.; KIRK, R. W. Kirk's current veterinary therapy - small animal practice XII, Philadelphia: W.B. Saunders, 2000. p.321-323.

14 RAMSEY, I. K.; EVANS, H.; HERRTAGE, M. E. Thyroid-stimulating hormoneb and total thyroxine concentrations in euthyroid, sick euthyroid and hypothyroid dogs. Journal of Small Animal Practice, v. 38, n. 12, p. 540-545, 1997.

15 FELDMAN, E. C.; NELSON, R. W. Canine and feline endocrinology and reproduction. $2^{\text {nd }} \mathrm{ed}$. Philadelphia: W.B. Saunders, 2004. 1089 p.

16 WISNER, E. R.; NYLAND, T. G. Ultrassonography of the thyroid and parathyroid glands. Veterinary Clinics of North America. Small Animal Practice, v. 28, n. 4, p. 973-991, 1998.

17 WISNER, E. R.; MATTOON, J. S.; NYLAND, T. G. BAKER, T. W. Normal ultrasonographic anatomy of the canine neck. Veterinary Radiology, v. 32, n. 4, p. 185-190, 1991.

18 BROWN, M. C.; SPENCER, R. Thyroid gland volume estimated by use of ultrasound in addition to 
scintigraphy. Acta Radiology Oncology, Radiat. Phys. Biol., v. 17, n. 4, p. 337-341, 1978.

19 CASTILLO, V.; ZEO, G.; CASAS, G.; LALIA, J.; PISAREV, M. Estudio ecografico y morfologico de la tiroides canina submetida a exceso de iodo dietario durante el crecimiento. In: CONGRESO SOCIEDAD LATINO-AMERICANA DE TIROIDES, 7., 1997, Chile. Anais... [ s. I.: s. n.], 1997.

20 JERICÓ, M. M. Avaliação das funções adrenal e tiroidea na espécie canina: padronização e comparação entre imunoensaios. 1998. 131 f. Tese (Doutorado em Clínica Médica) - Faculdade de Medicina Veterinária e Zootecnia, Universidade de São Paulo, São Paulo

21 PANCIERA, D. L. Hypothyroidism in dogs: 66 cases (1987-1992). Journal of American Veterinary Medical Association, v. 204, n. 5, p. 761-767, 1994.

22 PETTERSON, M. E.; MELIAN, C.; NICHOLS, R. Measurement of serum total thyroxine, triiodothyronine, free thyroxine, and thyrotropin concentrations for diagnosis of hypothyroidism in dogs. Journal of American Veterinary Medical Association, v. 211, n. 11, p. 1396-1401, 1997. 